\title{
STRUCTURAL DIMENSION OF SOCIAL CAPITAL IN POLAND. URBAN VERSUS RURAL AREAS
}

Agnieszka WOJEWÓDZKA-WIEWIÓRSKA, Department of European Policy, Public Finances and Marketing, Warsaw University of Life Sciences, ul. Nowoursynowska 166, 02-787 Warszawa, Poland, agnieszka_wojewodzka@sggw.pl

The article refers the issues of structural capital in Poland, measured by the number of the organization and an indicator of the number of organizations per 10 thousand inhabitants. Deliberations for this component of social capital were conducted at the regional level (NUTS 2). Spatial disparities and the differences between urban and rural areas in 2005-2014 were determined. Data source was a Local Data Bank prepared by Central Statistical Office of Poland. It was a clear regional differences in terms of the activity of foundations and social organizations. In all voivodeships saw an increase in the number of foundations and associations per 10 thousand inhabitants in the analyzed period, both in urban and in rural areas. In rural areas the increase was much greater than in the towns. In comparison with rural areas, a higher level of the structural social capital was observed in towns.

Keywords: associations and social organizations, foundations, social capital, structural capital, urban and rural areas

\section{INTRODUCTION}

Today, the very idea of social capital is of interest to the representatives of the various scientific disciplines, including economists, and the concept of social capital is very often discussed in literature (Wojewódzka, 2006; Sarracino, 2009; Klimowicz, Bokajło (ed.), 2010; Wojewódzka-Wiewiórska, 2011a; Skawińska (ed.), 2012). This concept is well known mainly thanks to the works of researchers, that is to say P. Bordieu, J. Coleman and R. Putnam, even though at present there are different approaches to it, and this results in a variety of interpretations and a multitude of definitions (Czapiński, 2013). As a result, there are some difficulties in operationalization of social capital, particularly in the field of measurement of this immaterial form of capital. In spite of the lack of conceptual uniformity and the application of various research approaches, researchers agree that it is a modern factor of socio-economic development which increases the effectiveness of the use of hard development factors (Antoci, Sabatini, Sodini, 2009; Wojewódzka-Wiewiórska, 2011b; Skawińska (ed.), 2012). It is considered to be one of the endogenous development factors at local and regional scale (Kłodziński, 2003; Wojewódzka, 2006; Heffner, 2007; Strzelecki (ed.), 2011; Wojewódzka-Wiewiórska, 2011c).

Social capital describes the relationships among people: social ties, norms of mutuality and mutual trust, and it is based on a willingness to cooperate. Social capital can be defined as a set of informal values and ethical norms that are shared by the members of a certain group of people, which enables them to effectively cooperate towards achieving their intended goals. Members of a particular social group, who believe that the remaining members will act honestly and reliably towards them, place their trust in them, which improves the effectiveness of the functioning of the group or institution (Fukuyama, 2003). Social capital is based on the features of social life and it comes into being when the particular actions and activities are approved by most members of the group. Social capital encompasses the ties of trust, loyalty and solidarity, which is reflected in self-organization and self-government, mainly within the framework of voluntary associations.

When conducting research on social capital in Poland, in particular on its measurement, one must be aware that an individualized approach is needed in this respect, which means that there is no opportunity to fully use research approaches taken in other countries. The abilities for self-organization of the country's population depend on diverse conditions that are specific to a given country and even to its particular regions. In Poland, very complicated historical factors are often taken into account, since they had a strong effect on the level of social capital today. Social involvement was determined by the three partitioning powers, various religions, changes of frontiers, communist regime or migrations, and the influence and impact of those factors on the formation of social capital varied from region to region.

The measurement of social capital is of particular importance from an economic perspective and it is important for the development of the very idea as well as for the opportunity of its practical implementation. Determination of the level of social capital encounters a number of difficulties (Theiss, 2005; Łopaciuk-Gonczaryk, 2012), which result, inter alia, from a multitude of definitions of social capital, type of the social capital under examination, level of the analysis and 
data availability. So far, there has been no precise way of measurement of social capital, and this problem is discussed by many researchers in literature (Westlund, 2006).

Various types of social capital are presented in literature. According to a broader approach (Krishna, Uphoff, 2002; Grootaert, Bastelaer, 2002; Theiss, 2005; Kaasa, Parts, 2007), the following components of social capital can be distinguished: structural, regulatory and behavioural. In this study the focus is on the structural dimension, which encompasses social organizations, social networks, groups and structures. At the same time, the analyses presented in the empirical Section refer to the work of Putnam, who linked social capital to the interaction of people and their involvement in various initiatives, first and foremost, the local ones.

The aim of the study is to define diversification of activities of non-governmental organizations in Poland in the town-village relationships and using spatial and temporal approach. It was based on the data taken from the Local Data Bank of the Central Statistical Office of Poland. A comparative analysis takes into consideration a regional approach (voivodship level) and local approach (county level). As regards temporal range, the analysis covers the years 2005-2014, and the detailed discussions that followed and their location in time were determined by data availability in the field of the problems tackled by the statistics in the public domain in Poland.

\section{THE NUMBER AND ACTIVITY OF ORGANIZATIONS IN POLAND}

According to the data from the REGON register, in Poland in 2014 there were 17, 605 registered cooperatives, 19,304 foundations and 107,876 associations and social organizations (Table 1). Among these legal bodies, associations dominated in Poland (74.5 percent), both in villages and in towns (Table 2). In villages, as compared to towns, the share of foundations in this group of entities was fairly low (4.5 percent).

Table 1. The number of selected legal forms of entities registered in REGON register in Poland *

\begin{tabular}{|l|c|c|c|c|c|}
\hline \multicolumn{1}{|c|}{ Specification } & $\mathbf{2 0 0 5}$ & $\mathbf{2 0 1 0}$ & $\mathbf{2 0 1 2}$ & $\mathbf{2 0 1 3}$ & $\mathbf{2 0 1 4}$ \\
\hline Cooperatives & 18303 & 17156 & 17155 & 17422 & 17605 \\
\hline Foundations & 8400 & 12444 & 15219 & 17098 & 19304 \\
\hline $\begin{array}{l}\text { Associations and social } \\
\text { organizations }\end{array}$ & 71121 & 92044 & 100299 & 104237 & 107876 \\
\hline Total & 97824 & 121644 & 138757 & 138757 & 144785 \\
\hline
\end{tabular}

* selected years are important from the point of view of analyzes carried later in the article

Source: own elaboration.

In the years 2005-2014, the number of cooperative societies slightly decreased, while the number of foundations increased nearly 2.3 times, and the number of associations grew by more than half ( 51.7 percent). In villages there functioned 32.7 percent of the entities under review, including 11 percent of foundations and 36.8 percent of associations and other social organizations.

Table 2. The selected legal forms of entities registered in REGON register in Poland in 2014

\begin{tabular}{|l|c|c|c|c|}
\hline \multicolumn{1}{|c|}{ Specification } & Cooperatives & Foundations & $\begin{array}{c}\text { Associations and social } \\
\text { organizations }\end{array}$ & Total \\
\hline total (pcs.) & 17605 & 19304 & 107876 & 144785 \\
\hline urban areas (pcs.) & 12075 & 17175 & 68189 & 97439 \\
\hline rural areas (pcs.) & 5530 & 2129 & 39686 & 47345 \\
\hline registered entities (pcs.) & 427 & 2324 & 4381 & 7132 \\
\hline deregistered entities (pcs.) & 204 & 155 & 560 & 919 \\
\hline urban areas (\%) & 68,6 & 89,0 & 63,2 & 67,3 \\
\hline rural areas (\%) & 31,4 & 11,0 & 36,8 & 32,7 \\
\hline
\end{tabular}

Source: own elaboration.

In 2014, as compared to 2005, the number of cooperatives, foundations and associations grew by 48 percent. In 2012 , 83.5 thousand organizations operated in an active way: most of them had their headquarters in the Mazowieckie (16.1 percent), Wielkopolskie (10.1 percent), Małopolskie (8.9 percent) and Śląskie (8.4 percent) Voivodships. A great number of organizations functioning in the above-mentioned voivodships is mostly the result of their large areas and population numbers. The lowest share of these entities was observed in the Lubuskie and Opolskie Voivodships (2.7 percent each).

The operation of active foundations and associations was also analyzed from the perspective of the character of a commune. The analysis of urban communes in Poland (organizations in urban communes $=100$ percent) conducted in 2012 showed that the shares of the organizations from the Mazowieckie (22.5 percent) and Śląskie (11.6 percent) Voivodships were the highest ones. As regards rural areas in the organizational structure in Poland, their highest share was observed in the Wielkopolskie (11.7 percent), Mazowieckie and Małopolskie Voivodships (about 10 percent each), as well as in the Podkarpackie and Lubelskie Voivodships (8.5 percent each). In urban-rural communes, the shares of the organizations from the Wielkopolskie (17.6 percent) and Małopolskie (9.6 percent) Voivodships were the highest ones. In the analyses conducted in this study, the Mazowieckie Voivodship had the highest index values, which may not necessarily be due to a high level of citizen activity of the inhabitants of the voivodship as a whole but to the presence of Warsaw and many all-Poland organizations seated in Poland's capital. 


\section{SPATIAL DIFFERENTIATION OF STRUCTURAL CAPITAL}

In order to show regional differentiation of the activity of organizations, the index of the number of foundations, associations and social organizations as per 10 thousand inhabitants was used. In 2014, the highest number of those entities as per 10 thousand inhabitants was recorded in the Mazowieckie, Warmińsko-Mazurskie and Dolnośląskie Voivodships, while the lowest number of organizations was observed in the Śląskie Voivodship (Figure 1). Taking into account the situation in the year 2005, the analysis shows the increase in the index value in all regions, the greatest improvement of the index being observed in the Mazowieckie, Dolnośląskie and Zachodniopomorskie Voivodships, and the smallest improvement of the index value being recorded in the Śląskie Voivodship.
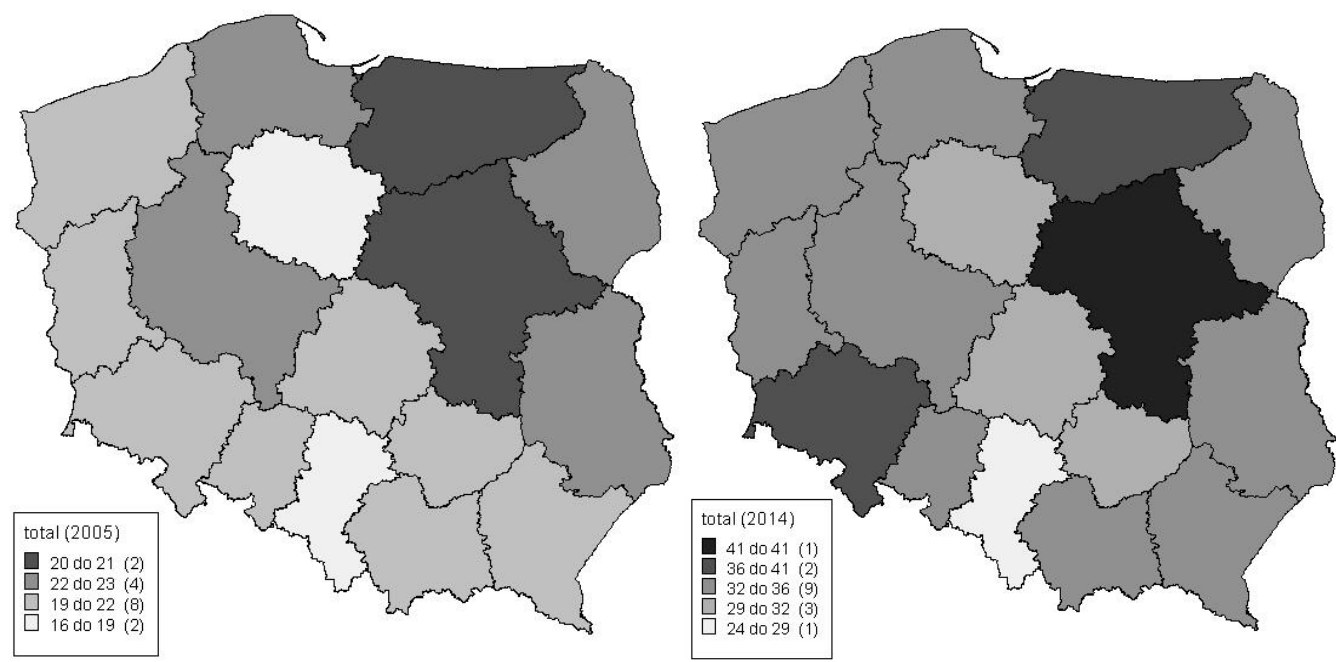

Figure 1. The number of foundations, associations and social organizations per 10 thousand inhabitants in Poland by voivodship (NUTS 2) in 2005 and 2014

Source: own elaboration.
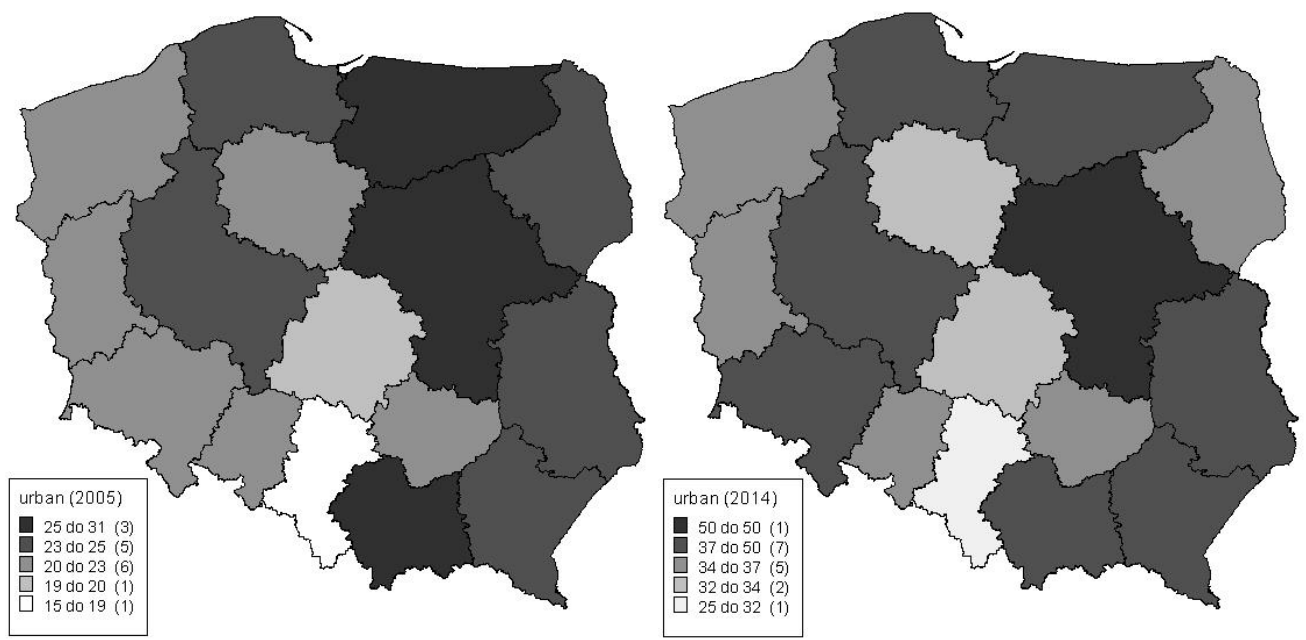

Figure 2. The number of foundations, associations and social organizations per 10 thousand inhabitants in urban areas in Poland by Source: own elaboration. voivodship (NUTS 2) in 2005 and 2014

In the period under examination, there was also a significant increase in the number of entities in towns (Figure 2); in 2014 a greater regional differentiation was observed than in 2005 (the gap amounted to 25). Only one voivodship (Ślaskie) was characterized by the index the value of which was contained in the interval for the year 2005. At the same time, in this region the index for 2014 was two times lower than that in the Mazowieckie Voivodship, which had the highest index value. Taking into consideration the variations of the index in the years 2005-2014, a similar regularity was observed in towns as well as in every voivodship as a whole, that is to say the highest increase was recorded in the Mazowieckie Voivodship (by 19 entities per 10 thousand inhabitants), and the lowest increase was observed in the Śląskie and Podlaskie Voivodships. The Śląskie Voivodship still remained the region with the relatively lowest level of the structural social capital. There is still a clear-cut distinction between a more active eastern part of Poland (except for the Podlaskie Voivodship) and a less active western part of the country. 

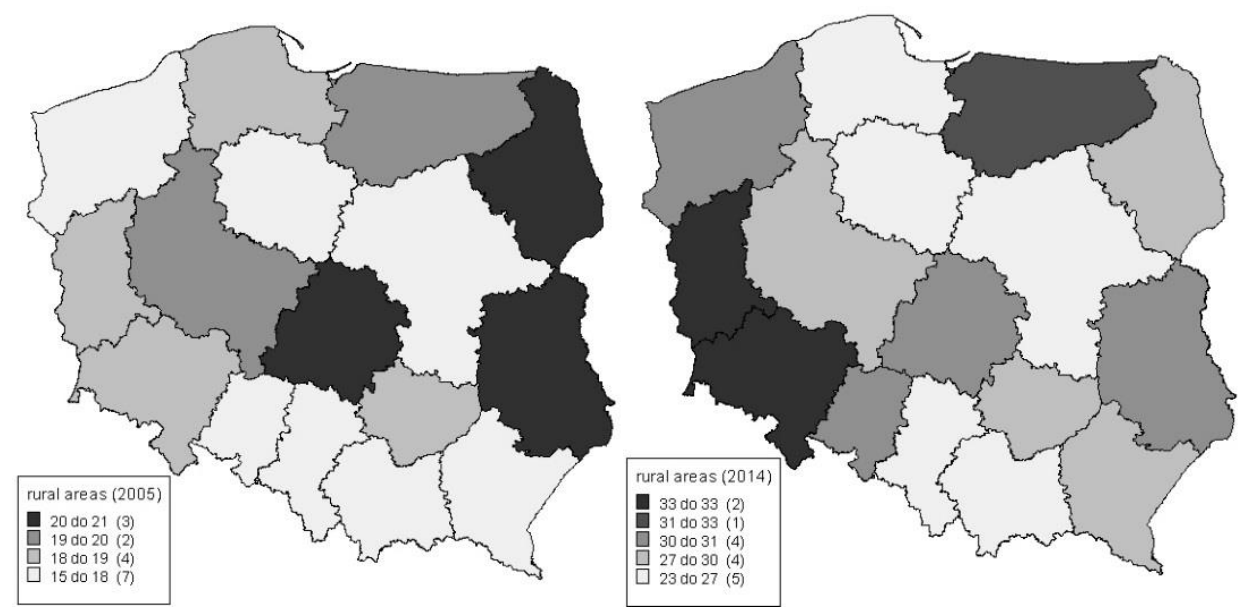

Figure 3. The number of foundations, associations and social organizations per 10 thousand inhabitants in rural areas in Poland by Source: own elaboration. voivodship (NUTS 2) in 2005 and 2014

Invariably, the activity of the organizations in villages is definitely smaller than that in towns. In the countryside, the indices also increased definitely, the highest increases being observed in the Dolnośląskie and Lubuskie Voivodships, followed by the Zachodniopomorskie and Opolskie Voivodships (Fig. 3). This resulted in the strengthening of the position of the western part of Poland. The lowest increases in the index value were observed in villages in the Śląskie and Małopolskie Voivodships. In the group of voivodships with a relatively lowest index value there remained the Śląskie, Małopolskie and Mazowieckie Voivodships, as well as the Kujawsko-Pomorskie Voivodship together with the Pomorskie Voivodship. In rural areas in the Mazowieckie Voivodship a small number of organizations in the period under review was observed as compared to the situation in towns. In 2005, the highest values of the index were observed in the voivodships of eastern Poland (Lubelskie and Podlaskie) and in the Łódzkie Voivodship, while in 2014 such values were recorded in the voivodships of western Poland (Dolnośląskie and Lubuskie) as well as in the Warmińsko-Mazurskie Voivodship.

\section{STRUCTURAL CAPITAL ON LOCAL LEVEL}

The earlier observation concerning regional differentiation of the number of foundations and associations as per 10 thousand inhabitants in Poland can also be applied to the local approach, that is to say in the cross-section of counties (in 2012), both in terms of a general approach and of the town-village subdivision. Apart from the Warmińsko-Mazurskie, Lubelskie, Lubuskie and Dolnośląskie Voivodships, which were characterized by high indices, there are no homogeneous voivodships, and the system has a mosaic character. There are clusters of counties with similar (high or low) values of the index. In addition to the above-mentioned voivodships, positive values of the index were observed in the north-western part of Poland, the southern part of the Wielkopolskie Voivodship and the south-eastern part of the Podkarpackie Voivodship. A definitely mosaic system occurred in the Mazowieckie Voivodship, where counties with the lowest activity of the organizations were dominant.
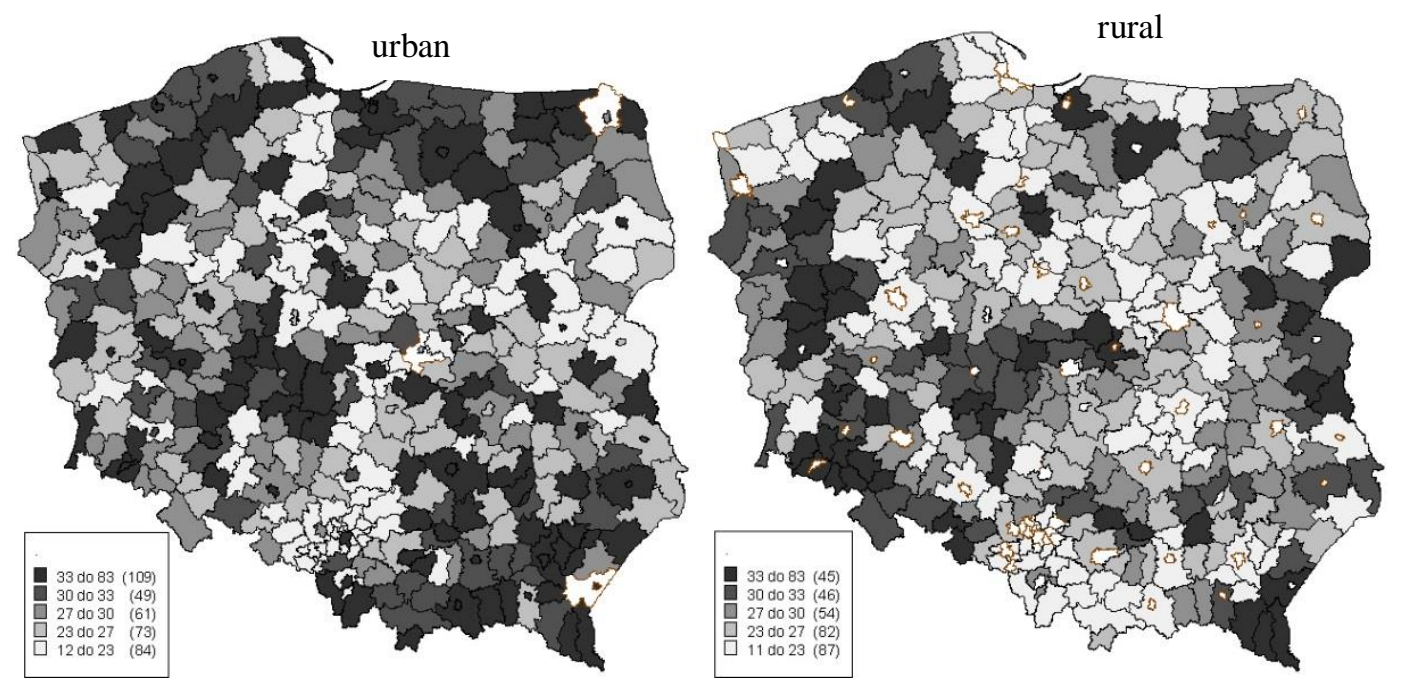

Fig. 4. The number of foundations, associations and social organizations per 10 thousand inhabitants in urban and rural areas in

Source: Wojewódzka-Wiewiórska, 2014.

Poland by counties (NUTS 4) in 2012 
Differentiation of the indices concerning the organizations in towns (Fig. 4) was similar to the situation described earlier for the counties as a whole, the greater homogeneity being observed in the south-eastern part of Poland, where the index values were relatively high. As regards villages, clusters of counties with high indices are smaller and less sparsely distributed on the map. Regions with the highest values (the index higher than 40 organizations) include the following counties: Bieszczady, Lesko, Międzychód, Głubczyce, Międzyrzecz, Parczew, Złotoryja, Polkowice and Hajnówka. As compared to towns, the southern and north-eastern parts of the country had definitely lower index values, and the counties of the Łódzkie Voivodship had higher indices.

\section{CONCLUSIONS}

The following conclusions were drawn on the basis of the analysis:

1. In 2012 in Poland there were 83.5 thousand actively operating foundations, associations and social organizations, most of which functioned in the Mazowieckie Voivodship (16.1 percent), Wielkopolskie Voivodship (10.1 percent), Małopolskie Voivodship (8.9 percent) and Śląskie Voivodship (8.4 percent); the lowest indices were observed in the Lubuskie and Opolskie Voivodships (2.7 percent in each one of them).

2. In 2014 , the largest number of foundations, associations and social organizations as per 10 thousand inhabitants was recorded in the Warmińsko-Mazurskie, Mazowieckie and Dolnośląskie Voivodships, and the smallest number of these entities was observed in the Śląskie Voivodship. As compared to 2005, the occurrence of a much higher regional differentiation in this respect was observed.

3. All the regions recorded the increase in the number of foundations and associations as per 10 thousand inhabitants in the years 2005-2014, both in towns and in villages. In rural areas this was a very significant increase. Still, however, the level of activity of the organizations in villages, as compared to towns, is definitely lower, which is evidenced by the values of the number of organizations as per 10 thousand inhabitants. However, one should take into consideration the fact that a specific feature of self-organization of the villagers is an informal character of interaction, and therefore some forms of this organization cannot be found in the statistics.

4. Regional differentiation of the number of foundations and associations as per 10 thousand inhabitants in Poland can also be seen at a local level (county level), both in terms of a general approach and in subdivision into towns and villages. In comparison with rural areas, a higher level of the structural social capital was observed in towns.

5. Statistical data on the problems discussed in this study that are available in the public domain in Poland are very limited; there is a lack of the particular data categories and there is no temporal continuity in data availability. Moreover, the sparse and fragmentary character of the data is observed regardless of the level of the analysis (at both local and regional scale) and it also concerns the town-village category. This situation impedes the research work and it results in difficulties in identification of actively operating organizations and of temporal variations in this respect. Very often data are taken from the REGON register, which - despite the obligation to enter an organization into the register - is rarely updated, and in fact the register includes entities which actually do not function. Thus, there is a practical necessity for the combination of the data from various sources, where of particular importance is a more indepth research that describes accurately the determinants and the way of operation of the various organizations being an expression of self-organization of the inhabitants.

\section{REFERENCES}

1. Antoci, A., Sabatini, F., Sodini, M. 2009. Fragility of Social Capital, University of Siena, pp. 1-8.

2. Local Data Bank, Central Statistical Office of Poland, 2005-2014, www.stat.gov.pl (accessed on 14/04/2014).

3. Czapiński, J. 2013. The state of civil society. Social capital. Social Diagnosis 2013. Conditions and quality of life of Poles. Report, Czapiński, J., Panek, T. The Council for Social Monitoring, Warsaw, pp. 285-297.

4. Fukuyama, F. 2003. Social capital. Harrisom L. E., Huntington S. P. (ed.), Culture is important, Zysk i S-ka, Poznań.

5. Grootaert, Ch., van Bastelaer, Th. 2002. Conclusion: Measuring Impact and Drawing Policy Implications. Grootaert Ch., Bastelaer Th. Van, The Role of Social Capital in Development. An Empirical Assessment, Cambridge University Press.

6. Heffner, K. 2007. Socio-economic development of rural areas. Definitions-conditions-relationships-Factors-Effects. Research diversify rural development, [in:] Rosner A., (ed.), Different levels of socio-economic development of rural areas and diversification dynamics of change, IRWiR PAN, Warsaw.

7. Kaasa A., Parts E., 2007, Individual - Level Determinants of Social Capital in Europe: Differences Between Country Groups, Tartu University Press, Tartu.

8. Klimowicz, M., Bokajło, W. 2010. Social capital- interpretations, impressions, operationalization, Wydawnictwo Fachowe CeDeWu.pl, Warsaw.

9. Kłodziński, M. 2003. Social capital as the main factor differentiating the degree of economic and social development of rural communities. Adamowicz M. (ed.), The local development strategies. Institutional aspects, Vol I, Wydawnictwo SGGW, Warszawa.

10. Krishna A., Uphoff N., 2002, Mapping and Measuring Social Capital Trough Assessment of Collective Action to Conserve and Develop Watersheds in Rajasthan, India. Grootaert Ch., Bastelaer Th. Van, The Role of Social Capital in Development. An Empirical Assessment, Cambridge University Press.

11. Łopaciuk - Gonczaryk B., 2012, Measuring social capital. The National Economy, No. 1-2, pp. 1-23. 
12. Sarracino, F. 2009. Social Capital and Subjective Well-Being trends: Evidence from 11 European countries, University of Siena.

13. Skawińska, E. 2012. Social capital in the region's development, Wydawnictwo Naukowe PWN, Warsaw.

14. Strzelecki, Z. 2011. Regional and local economy in Poland. Factors and barriers, Oficyna Wydawnicza SGH w Warsaw, Warsaw.

15. Theiss, M. 2005. Operationalization of social capital in empirical research. Social capital in communities, Januszek H. (ed.), Wyd. AE in Poznaniu, Poznań.

16. Westlund, H. 2006. Social Capital in the Knowledge Economy: Theory and Empirics, Springer Berlin.

17. Wojewódzka, A. 2006. The importance of social capital in local development. Adamowicz M. (ed.), Local governments and local communities in the sustainable development of rural areas, SGGW Warsaw.

18. Wojewódzka-Wiewiórska, A. 2011a. Determinants of rural areas development in the theory. Development Prospects of Rural Areas Lagging Behind in the CEE Region, Conference Proceeding, L. Villanyi, Gödöllö.

19. Wojewódzka-Wiewiórska, A. 2011b. The need to build social capital in rural areas. Wieś Jutra, No. 11/12 (160/161), pp. 17-18.

20. Wojewódzka-Wiewiórska, A. 2011c. Social capital as an endogenous factor of local development, Roczniki Naukowe SERiA, Tom XIII, Zeszyt 6, Warsaw-Poznań- Wroclaw.

21. Wojewódzka-Wiewiórska, A. 2014. The structural dimension of social capital in Poland. Rękas M., Sokołowski J. (ed), Economics, Prace Naukowe UE Wrocław, No. 347, Wrocław, pp. 513-523. 